\title{
Analisis Perbandingan Kinerja Struktur Baja SRBKK Tipe Inverted-V pada Gedung Bertingkat 12, 16, dan 20 Lantai
}

\author{
DIVA RAHMA BENITA, ERMA DESMALIANA, AMATULHAY PRIBADI
}

Jurusan Teknik Sipil Institut Teknologi Nasional Bandung

Email: dirahmanita@yahoo.com

\begin{abstract}
ABSTRAK
Konstruksi baja merupakan suatu alternatif yang dapat digunakan dalam pembangunan gedung tinggi. Salah satu cara untuk memperbesar kekakuan suatu gedung dengan memasang bresing. Pada kasus ini sistem struktur baja yang digunakan yakni Sistem Rangka Bresing Konsentrik Khusus menggunakan bresing tipe Inverted-V. Dalam tugas akhir ini dilakukan perencanaan struktur baja bertingkat 12, 16 dan 20 lantai yang dimana nantinya juga dilakukan evaluasi kinerja struktur bangunan menggunakan analisis pushover untuk menentukan struktur bangunan yang paling efektif dalam perencanaan struktur menggunakan bresing Inverted-V. Dalam tugas akhir ini, didapat level kinerja struktur pada struktur baja bertingkat 12, 16 dan 20 lantai berada pada kinerja Immediate Occupancy (IO). Dari hasil-hasil analisis yang diperoleh dapat disimpulkan bahwa struktur baja bertingkat 12 lantai menggunakan bresing konsentrik tipe Inverted-V memiliki perioda struktur yang paling kecil dan berat struktur yang lebih kecil dibandingkan sistem rangka bresing struktur lainnya.
\end{abstract}

Kata kunci: struktur baja, pushover, kinerja struktur

\begin{abstract}
Steel construction is an alternative that can be used in the construction of tall buildings. One way to increase the rigidity of a building by installing the bracing. In this case the steel structure system that will be used is the Steel Special Concentrically using Inverted-V type bracing. In this thesis, steel structure planning of 12, 16 and 20-storey will be carried out, which will also evaluate the performance of the building structure using pushover analysis to determine the most effective structure in the structure planning using Inverted-V bracing. In this thesis, it obtained the level structural performance in steel structure 12, 16 and 20-storey floors are in the performance of Immediate Occupancy (IO). From the result of the analysis that was obtained, it can be concluded that the 12storey steel structure steel structure using concentrically Inverted V-braced frames has the smallest structural period and smaller structural weights compared to other structural bracing systems.
\end{abstract}

Keywords: steel structure, pushover, structure performance 


\section{PENDAHULUAN}

Indonesia merupakan negara yang terletak di jalur Ring of Fire kawasan Pasifik dan menjadi pusat pertemuan 3 lempeng tektonik utama yaitu Lempeng Indo-Australia, Lempeng Eurasia, dan Lempeng Pasifik. Sehingga fakta mengatakan bahwa Indonesia rawan terjadinya gempa. Oleh karena itu, bangunan-bangunan tinggi di Indonesia harus dirancang sedemikian rupa untuk meminimalisir kerusakan yang terjadi akibat gempa.

Konstruksi baja merupakan suatu alternatif yang dapat digunakan dalam pembangunan gedung tinggi karena kuat. Salah satu cara untuk memperbesar kekakuan suatu gedung terutama pada bangunan tinggi adalah dengan memasang bresing atau batang penopang.

Adapun berbagai tipe rangka bresing dari Sistem Rangka Bresing Konsentrik Khusus (SRBKK) yang umum digunakan yaitu tipe diagonal, tipe $\mathrm{V}$, tipe inverted- $\mathrm{V}$, dan tipe $\mathrm{X}$ seperti yang dapat dilihat pada Gambar 1.

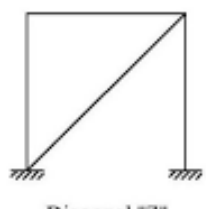

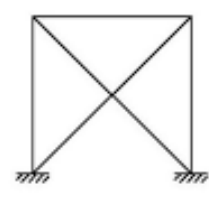

"X"

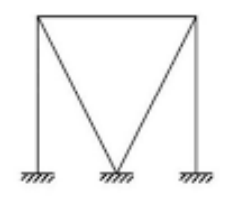

"V"

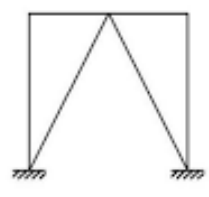

Inverted $\mathrm{V}$ " $\mathrm{\Lambda}$ "

Gambar 1. Tipe bresing pada SRBKK

(Sumber: Aryandi, D. \& Herbudiman, B., 2017)

Pada kasus ini rangka bresing yang digunakan yakni tipe inverted-V yang memiliki daktilitas paling tinggi dibandingkan bresing tipe lainnya (Aryandi, D. \& Herbudiman, B., 2017). Tujuan dari penelitian ini adalah melakukan perencanaan struktur baja menggunakan Sistem Rangka Bresing Konsentrik Khusus (SRBKK) tipe Inverted-V dan tanpa bresing Inverted-V, mengetahui besarnya nilai kekakuan yang terjadi pada struktur baja apabila menggunakan sistem rangka bresing tipe inverted- $\mathrm{V}$ dan tanpa menggunakan sistem rangka bresing tipe inverted-V dan melakukan evaluasi kinerja struktur bangunan analisis pushover.

\section{TINJAUAN PUSTAKA}

\subsection{Sistem Bresing Inverted-V}

Pada sistem bresing tipe inverted- $\mathrm{V}$, kedua batang diagonal akan sama-sama menahan beban horizontal. Beban gravitasi juga mengakibatkan gaya aksial bresing inverted-V. Ketika bresing menahan balok pada tengah bentang, akan mengurangi bentang balok efektif dan kapasitas momen plastis yang terjadi (ASCE, 1971). Bresing tipe inverted-V dapat dilihat pada Gambar 2.

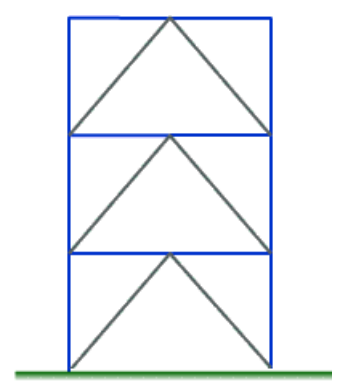

Gambar 2. Bresing inverted-V (Sumber: www.ideers.bris.ac.uk) 


\subsection{Analisa Pushover}

Analisa pushover merupakan salah satu analisa untuk mengetahui perilaku keruntuhan suatu struktur bangunan terhadap gempa, dikenal juga dengan istilah beban statik dorong. Analisa ini dilakukan dengan mengaplikasikan suatu beban yang nantinya nilai beban tersebut akan ditingkatkan secara berangsur-angsur atau bertahap pada suatu struktur sampai dengan kondisi tertentu yang diinginkan, sehingga didapat gambaran perilaku struktur baik sebelum mengalami leleh pertama kali ataupun sesudahnya sampai mencapai keruntuhan.

Hasil akhir yang didapatkan dari analisa pushover ini adalah berupa kurva kapasitas yang menggambarkan hubungan antara gaya geser dasar (base shear, V) dengan perpindahan titik acuan atau simpangan pada atap (roof displacement, D).

Mengacu pada FEMA-356 terdapat 4 macam klasifikasi level kinerja struktur yang menjadi acuan bagi perencana yaitu:

1. Operasional (Operationa)

Taraf ini merupakan kondisi dimana dapat diindikasikan tidak ada kerusakan struktural maupun non-struktural yang berarti pada struktur.

2. Penghunian Segera (Immediate Occupacy / IO)

Taraf ini merupakan kondisi dimana diindikasikan tidak ada kerusakan berarti pada struktur. Kerusakan dan kekakuan struktur kira-kira sama dengan kondisi sebelum terjadi gempa bumi. Komponen non-struktural masih berada pada tempatnya dan sebagian besar masih berfungsi jika utilitasnya masih ada. Bangunan tetap dapat berfungsi tanpa terganggu masalah perbaikan.

3. Keselamatan Jiwa (Life Safety / LS)

Taraf ini merupakan kondisi dimana diindikasikan telah terjadi kerusakan pada elemen struktur tetapi masih bersifat daktail. Komponen non-struktural masih ada tetapi sudah tidak berfungsi. Bangunan bisa digunakan kembali setelah perbaikan.

4. Stabilitas Struktur (Collapse Preventation atau Structural Stability / CP)

Taraf ini merupakan kondisi dimana diindikasikan telah terjadi kerusakan pada elemen struktural dan non-struktural. Bangunan hampir runtuh dan sudah tidak dapat digunakan kembali.

\subsection{Pembebanan Akibat Gravitasi}

Dalam perencanaan struktur ini menggunakan pembebanan yang direncanakan menurut Beban Minimum untuk Perancangan Bangunan Gedung dan Struktur Lain (SNI-03-17272013). Adapun beban-beban yang bekerja dalam perencanaan struktur ini adalah sebagai berikut:

1. Beban Mati (Dead Load)

Beban mati adalah berat sendiri struktur tersebut yang terdiri dari berat jenis baja 78,5 $\mathrm{kN} / \mathrm{m}^{3}$ dan beton bertulang $24 \mathrm{kN} / \mathrm{m}^{3}$. Berat sendiri akan dihitung secara otomatis dengan bantuan aplikasi ETABS 2015.

2. Beban Hidup (Live Load)

Beban hidup adalah beban yang diakibatkan oleh pengguna dan penghuni bangunan gedung atau struktur lain. Beban hidup pada gedung apartemen yaitu sebesar 4,79 $\mathrm{kN} / \mathrm{m}^{2}$.

3. Beban Mati Tambahan (SiDL)

Beban mati tambahan yang digunakan berdasarkan peraturan pembebanan SNI-031727-1989 yaitu langit-langit dan penggantung, berat Mechanical Electrical, spesi, penutup lantai dan water proofing.

4. Beban Gempa

Pada perencanaan struktur ini menggunakan data respon spektrum yang didapat dari 
web resmi Pusat Penelitian dan Pengembangan Perumahan dan Pemukiman yaitu http://puskim.pu.go.id/ untuk wilayah yang digunakan adalah daerah Padang, Sumatera Barat.

\subsection{Analisis Beban Gempa Statik Ekivalen}

Dalam menganalisis beban gempa secara statik ekivalen perlu diperhatikan faktor-faktor sebagai berikut:

1. Geser Dasar Seismik

Berdasarkan SNI 1726-2012, gaya geser dasar seismik (V), dalam arah yang ditetapkan harus sesuai dengan Persamaan 1.

$$
V=C_{s} W
$$

halmana:

$W$ = berat total gedung,

$C_{s}=$ koefisien respons seismik.

2. Perioda Fundamental Pendekatan

Perioda fundamental pendekatan $\left(T_{a}\right)$ dalam detik, harus ditentukan dari Persamaan 2.

$$
T_{a}=C_{t} h_{n}^{x}
$$

halmana:

$h_{n}=$ ketinggian struktur dalam meter diatas dasar sampai tingkat tertinggi struktur, $C_{t}=$ ditentukan dari Tabel 15 SNI 1726-2012.

3. Penentuan Simpangan Antar Lantai

Penentuan simpangan antar lantai tingkat desain $(\Delta)$ harus dihitung sebagai perbedaan defleksi pada pusat massa di tingkat teratas dan terbawah yang ditinjau. Defleksi pusat massa di tingkat $x\left(\delta_{x}\right)$ harus ditentukan sesuai dengan Persamaan 3.

$$
\delta_{x}=\frac{c_{d} \delta_{x e}}{I_{e}}
$$

halmana:

$\delta_{x}=$ simpangan antar lantai [mm],

$C_{d}=$ faktor amplifikasi defleksi,

$\delta_{x e}=$ defleksi pada lokasi yang ditentukan dengan analisis elastis [mm],

$I_{e}=$ faktor keutamaan.

Simpangan antar lantai tingkat desain $(\Delta)$ tidak boleh melebihi simpangan antar lantai tingkat izin $\left(\Delta_{a}\right)$ yang didapatkan sesuai dengan Persamaan 4.

$$
\Delta_{\text {izin }}=0,020 * h_{s x}
$$

halmana:

$\Delta_{i z i n}=$ simpangan antar lantai izin [mm],

$h_{s x}=$ ketinggian setiap lantai $[\mathrm{mm}]$.

4. Modal Partisipasi Massa

Berdasarkan SNI 1726-2012 nilai analisis harus menyertakan jumlah ragam yang cukup untuk mendapatkan partisipasi massa ragam terkombinasi sebesar paling sedikit $90 \%$ dari massa aktual dalam masing-masing arah horizontal orthogonal dari respon yang 
ditinjau oleh model.

\section{METODOLOGI PENELITIAN}

\subsection{Studi Literatur}

Studi literatur yang digunakan dalam penelitian Analisis Perbandingan Kinerja Struktur Baja SRBKK Tipe Inverted-V pada Gedung Bertingkat 12, 16, dan 20 Lantai adalah sebagai berikut:

1. Konsep perencanaan struktur tahan gempa.

2. Perencanaan struktur rangka baja.

3. Konsep desain bresing konsentruk khusus.

4. Pembahasan tentang analisis pushover.

\subsection{Penentuan Layout dan Dimensi Gedung}

Desain bangunan gedung yang digunakan dalam penelitian ini adalah sebagai berikut:

1. Lokasi bangunan : Kota Padang

2. Fungsi bangunan : gedung apartemen

3. Bentuk bangunan

a. Gedung 12 lantai

Jumlah lantai : 12 lantai + atap

Tinggi total gedung : 47,00 meter

Panjang gedung : 42,00 meter

Lebar gedung : :35,00 meter

b. Gedung 16 lantai

Jumlah lantai $\quad: 16$ lantai + atap

Tinggi total gedung : 63,00 meter

Panjang gedung : 42,00 meter

Lebar gedung : : 35,00 meter

c. Gedung 20 lantai

Jumlah lantai : 20 lantai + atap

Tinggi total gedung : 79,00 meter

Panjang gedung : 42,00 meter

Lebar gedung : : 35,00 meter

\subsection{Preliminary Design, Input Data Struktur dan Pembebanan}

Preliminary design yang dilakukan dalam penelitian ini ditentukan dengan cara trial and error. Adapun data yang digunakan dalam preliminary design antara sebagai berikut:

Material

: baja

Mutu baja : BJ-41

Tegangan leleh $\left(f_{y}\right) \quad: 250 \mathrm{MPa}$

Tegangan ultimate $\left(f_{u}\right) \quad: 410 \mathrm{MPa}$

Modulus elastisitas $(E) \quad: 200.000 \mathrm{MPa}$

\section{PEMODELAN STRUKTUR}

\subsection{Data Perencanaan Struktur}

Berikut tampilan struktur 3D pada gedung bertingkat 12, 16 dan 20 lantai, baik yang menggunakan bresing maupun tanpa menggunakan bresing, yang didesain pada penelitian ini. Adapun tampilan struktur 3D dapat dilihat pada Gambar $\mathbf{3}$ di bawah ini. 


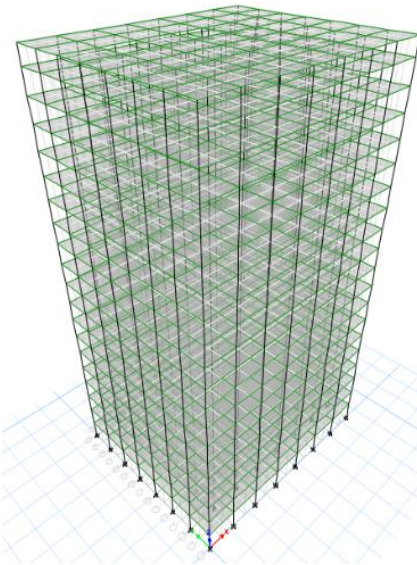

(a)

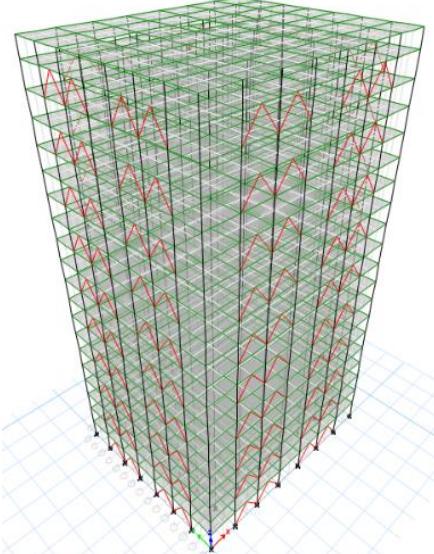

(d)

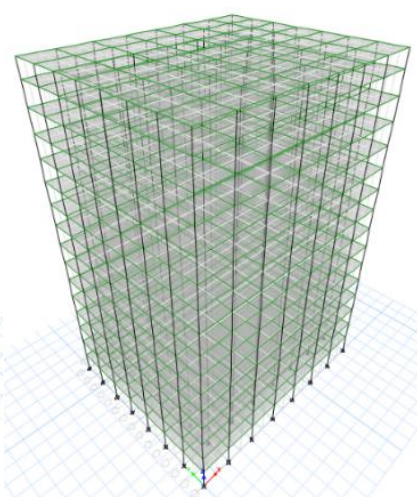

(b)

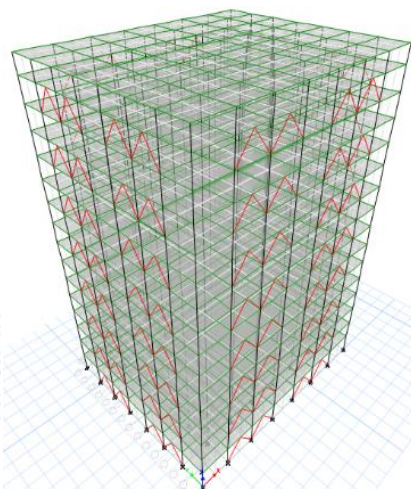

(e)

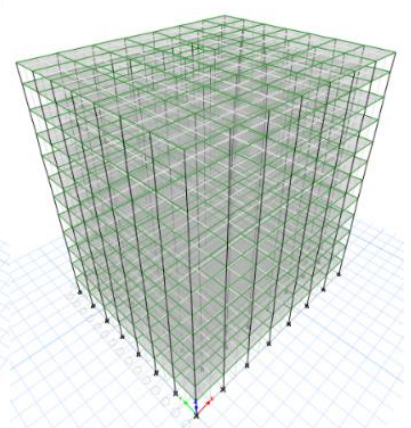

(c)

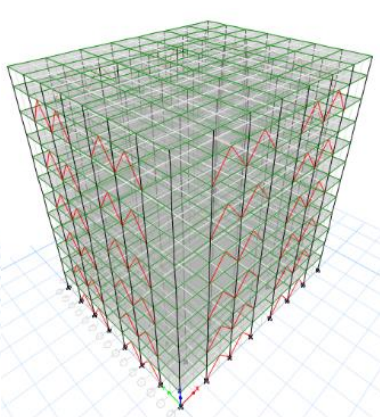

(f)

Gambar 3. Tampak 3D struktur gedung: (a) 20 lantai; (b) 16 lantai; (c) 12 lantai;

(d) 20 lantai dengan bresing; (e) 16 lantai dengan bresing; (f) 12 lantai dengan bresing.

\section{PEMBAHASAN}

\subsection{Periode Struktur}

Dari hasil analisis yang dilakukan oleh alat bantu ETABS 2015 didapatkan perioda struktur dimana pada struktur tanpa bresing perioda struktur yang didapat lebih dari batas perioda maksimum yang ditentukan. Maka perioda struktur yang diambil yaitu sama dengan perioda maksimum. Sedangkan pada struktur dengan bresing hasil perioda struktur yang didapat dari ETABS 2015 sudah berada pada range perioda minimum dan perioda maksimum. Berikut hasil analisa perioda struktur dapat dilihat pada Tabel 1.

Tabel 1. Perbandingan Perioda Struktur

\begin{tabular}{cccc}
\hline \multicolumn{1}{c}{ Tipe Struktur } & Arah & \multicolumn{1}{c}{$\begin{array}{c}\boldsymbol{T} \\
\text { [s] }\end{array}$} \\
\hline \multirow{3}{*}{12 lantai } & tanpa bresing & $\mathrm{X}$ & 1,819 \\
\cline { 2 - 3 } & \multirow{2}{*}{ dengan bresing } & $\mathrm{Y}$ & 1,819 \\
\cline { 2 - 3 } & $\mathrm{X}$ & 1,405 \\
\cline { 2 - 3 } & $\mathrm{Y}$ & 1,725 \\
\hline
\end{tabular}


Tabel 1. Perbandingan Perioda Struktur lanjutan

\begin{tabular}{cccc}
\hline \multicolumn{1}{c}{ Tipe Struktur } & Arah & \multicolumn{1}{c}{$\begin{array}{c}\boldsymbol{T} \\
\text { [s] }\end{array}$} \\
\hline \multirow{3}{*}{16 lantai } & tanpa bresing & $\mathrm{X}$ & 2,266 \\
\cline { 2 - 4 } & \multirow{2}{*}{ dengan bresing } & $\mathrm{Y}$ & 2,266 \\
\cline { 2 - 4 } & $\mathrm{X}$ & 1,914 \\
\cline { 2 - 3 } 20 lantai & $\mathrm{Y}$ & 2,225 \\
\cline { 2 - 4 } & \multirow{2}{*}{ tanpa bresing } & $\mathrm{X}$ & 2,686 \\
\cline { 2 - 4 } & \multirow{2}{*}{ tengan bresing } & $\mathrm{Y}$ & 2,686 \\
\cline { 2 - 3 } & $\mathrm{X}$ & 2,445 \\
\hline
\end{tabular}

\subsection{Gaya Geser Dasar}

Dari hasil analisis yang dilakukan oleh alat bantu ETABS 2015 didapatkan gaya geser dasar tiap struktur dimana gaya geser analisis lebih kecil dibandingkan gaya geser statis. Maka gaya geser dasar sudah memenuhi syarat. Berikut hasil analisis gaya geser dasar struktur pada struktur bertingkat 12, 16 dan 20 lantai dapat dilihat pada Tabel 2.

Tabel 2. Perbandingan Gaya Geser Dasar

\begin{tabular}{|c|c|c|c|c|c|c|}
\hline \multicolumn{2}{|c|}{ Tipe Struktur } & \multirow{2}{*}{$\begin{array}{c}\text { Arah } \\
X \\
\end{array}$} & \multirow{2}{*}{$\begin{array}{c}\begin{array}{c}\boldsymbol{V}_{\text {statis }} \\
\text { [kN] }\end{array} \\
2.596,287\end{array}$} & \multirow{2}{*}{$\begin{array}{c}\begin{array}{c}\boldsymbol{V}_{\text {dinamis }} \\
{[\mathbf{k N}]}\end{array} \\
3.571,598\end{array}$} & \multirow{2}{*}{$\begin{array}{c}\begin{array}{c}\mathbf{0}, \mathbf{8 5} \mathbf{V}_{\text {statis }} \\
\text { [kN] }\end{array} \\
2.207,983\end{array}$} & \multirow{2}{*}{$\begin{array}{c}\text { Keterangan } \\
\text { memenuhi syarat }\end{array}$} \\
\hline \multirow{4}{*}{12 lantai } & \multirow{2}{*}{ tanpa bresing } & & & & & \\
\hline & & $Y$ & $2.596,287$ & $3.297,787$ & $2.207,983$ & memenuhi syarat \\
\hline & & $\mathrm{X}$ & $4.550,797$ & $5.377,249$ & $3.868,178$ & memenuhi syarat \\
\hline & & $Y$ & $3.712,324$ & $5.012,617$ & $3.155,475$ & memenuhi syarat \\
\hline \multirow{4}{*}{16 lantai } & \multirow{2}{*}{ tanpa bresing } & $x$ & $3.371,767$ & $3.495,57$ & $2.866,002$ & memenuhi syarat \\
\hline & & $\mathrm{Y}$ & $3.371,767$ & $3.371,901$ & $2.866,002$ & memenuhi syarat \\
\hline & \multirow{2}{*}{ dengan bresing } & $x$ & $4.494,056$ & $5.629,44$ & $3.819,947$ & memenuhi syarat \\
\hline & & $Y$ & $3.869,349$ & $5.137,724$ & $3.288,947$ & memenuhi syarat \\
\hline \multirow{4}{*}{20 lantai } & \multirow{2}{*}{ tanpa bresing } & $x$ & $4.376,25$ & $3.902,534$ & $3.719,813$ & memenuhi syarat \\
\hline & & $Y$ & $4.376,25$ & $3.900,216$ & $3.719,813$ & memenuhi syarat \\
\hline & \multirow{2}{*}{ dengan bresing } & $x$ & $4.431,421$ & $5.611,642$ & $3.766,708$ & memenuhi syarat \\
\hline & & $Y$ & $3.998,030$ & $5.184,837$ & $2.888,326$ & memenuhi syarat \\
\hline
\end{tabular}

\subsection{Simpangan pada Atap}

Dari hasil analisis struktur yang dilakukan oleh ETABS 2015 bahwa struktur tersebut memenuhi syarat simpangan izin. Berikut hasil analisa simpangan pada atap dapat dilihat pada Tabel 3.

Tabel 3. Perbandingan Simpangan pada Atap

\begin{tabular}{ccccccccc}
\hline \multirow{2}{*}{ Story } & \multicolumn{2}{c}{$\begin{array}{c}\text { 12 Lantai } \\
\text { [m] }\end{array}$} & \multicolumn{2}{c}{$\begin{array}{c}\text { 16 Lantai } \\
\text { [m] }\end{array}$} & \multicolumn{2}{c}{$\begin{array}{c}\text { 20 Lantai } \\
\text { [m] }\end{array}$} & Simpangan Izin \\
\cline { 2 - 7 } & $\begin{array}{c}\text { Tanpa } \\
\text { Bresing }\end{array}$ & $\begin{array}{c}\text { Dengan } \\
\text { Bresing }\end{array}$ & $\begin{array}{c}\text { Tanpa } \\
\text { Bresing }\end{array}$ & $\begin{array}{c}\text { Dengan } \\
\text { Bresing }\end{array}$ & $\begin{array}{c}\text { Tanpa } \\
\text { Bresing }\end{array}$ & $\begin{array}{c}\text { Dengan } \\
\text { Bresing }\end{array}$ & Keterangan \\
\hline Roof & 0,0191 & 0,0069 & 0,0175 & 0,0066 & 0,0137 & 0,0115 & 0,08 & OK \\
\hline
\end{tabular}

\subsection{Modal Partisipasi Massa}

Dari hasil analisis struktur yang dilakukan oleh ETABS 2015 menunjukkan bahwa struktur tersebut memenuhi syarat minimal $90 \%$ respon total dari perhitungan respon dinamik. Berikut hasil partisipasi massa dari program ETABS 2015 dapat dilihat pada Tabel 4. 
Tabel 4. Perbandingan Modal Partisipasi Massa

\begin{tabular}{|c|c|c|}
\hline Tipe Struktur & Arah & $\begin{array}{c}\text { Partisipasi Massa } \\
{[\%]}\end{array}$ \\
\hline \multirow[b]{2}{*}{ tanpa bresing } & UX & 92,16 \\
\hline & UY & 97,41 \\
\hline \multirow{2}{*}{ dengan bresing } & UX & 92,29 \\
\hline & UY & 95,36 \\
\hline \multirow{2}{*}{ tanpa bresing } & UX & 91,59 \\
\hline & UY & 96,53 \\
\hline \multirow{2}{*}{ dengan bresing } & UX & 93,94 \\
\hline & UY & 94,82 \\
\hline \multirow{2}{*}{ tanpa bresing } & UX & 91,11 \\
\hline & UY & 95,55 \\
\hline \multirow{2}{*}{ dengan bresing } & UX & 93,59 \\
\hline & UY & 95,03 \\
\hline
\end{tabular}

\subsection{Berat Total Struktur}

Dari hasil analisis struktur yang dilakukan oleh ETABS 2015 didapatkan berat total struktur dari setiap pemodelan yang didesain. Pada tabel dibawah menunjukkan pemodelan struktur yang memiliki berat struktur yang paling besar yaitu struktur bertingkat 20 lantai dengan menggunakan bresing, hal ini dikarenakan adanya tambahan berat profil baja dari elemen bresing itu sendiri sehingga berat struktur menjadi lebih besar. Berikut hasil berat total struktur dari program ETABS dapat dilihat pada Tabel 5.

Tabel 5. Perbandingan Berat Struktur

\begin{tabular}{|c|c|c|c|}
\hline \multicolumn{2}{|c|}{ Tipe Struktur } & Arah & $\begin{array}{l}\text { Berat Total } \\
{[\mathbf{k g}]}\end{array}$ \\
\hline \multirow{4}{*}{12 lantai } & \multirow{2}{*}{ tanpa bresing } & $X$ & $6.301 .666,84$ \\
\hline & & $Y$ & $6.301 .666,84$ \\
\hline & \multirow{2}{*}{ dengan bresing } & $x$ & $6.400 .559,48$ \\
\hline & & $Y$ & $6.400 .559,48$ \\
\hline \multirow{4}{*}{16 lantai } & \multirow{2}{*}{ tanpa bresing } & $x$ & $8.467 .724,58$ \\
\hline & & $Y$ & $8.467 .724,58$ \\
\hline & \multirow{2}{*}{ dengan bresing } & $X$ & $8.609 .302,17$ \\
\hline & & $Y$ & $8.609 .302,17$ \\
\hline \multirow{4}{*}{20 lantai } & \multirow{2}{*}{ tanpa bresing } & $x$ & $10.679 .343,7$ \\
\hline & & $\mathrm{Y}$ & $10.679 .343,7$ \\
\hline & \multirow{2}{*}{ dengan bresing } & $x$ & $10.834 .771,86$ \\
\hline & & $Y$ & $10.834 .771,86$ \\
\hline
\end{tabular}

\subsection{Level Kinerja Struktur}

Berdasarkan hasil pushover dari program ETABS 2015 yang dipaparkan pada Tabel 6 didapat hasil kinerja struktur sebagai berikut.

Tabel 6. Level Kinerja Struktur

\begin{tabular}{cccccc}
\hline \multicolumn{2}{c}{ Tipe Struktur } & $\begin{array}{c}\text { Maximum } \\
\text { Drift }\end{array}$ & $\begin{array}{c}\text { Level } \\
\text { Kinerja }\end{array}$ & $\begin{array}{c}\text { Maximum } \\
\text { Drift }\end{array}$ & $\begin{array}{c}\text { Level } \\
\text { Kinerja }\end{array}$ \\
\hline \multirow{2}{*}{12 Lantai } & tanpa bresing & 0,007 & IO & 0,0086 & IO \\
\cline { 2 - 6 } & dengan bresing & 0,00327 & IO & 0,00323 & IO \\
\hline \multirow{2}{*}{16 Lantai } & tanpa bresing & 0,007 & IO & 0,008 & IO \\
\cline { 2 - 6 } & dengan bresing & 0,00361 & IO & 0,00229 & IO \\
\hline \multirow{2}{*}{20 Lantai } & tanpa bresing & 0,0068 & IO & 0,0076 & IO \\
\cline { 2 - 6 } & dengan bresing & 0,0042 & IO & 0,003 & IO \\
\hline
\end{tabular}




\subsection{Kurva Pushover}

Kurva pushover merupakan hasil output dari analisis pushover yang dilakukan oleh ETABS 2015. Kurva yang dihasilkan berupa kurva berpotongan antara kurva kapasitas, kurva demand dan kurva respon spektrum. Berikut kurva pushover yang dihasilkan oleh ETABS 2015 dapat dilihat pada Gambar 4, Gambar 5, dan Gambar 6.

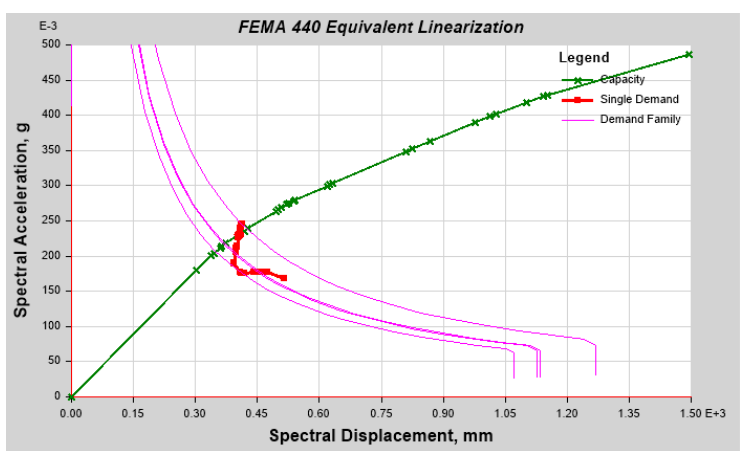

(a)

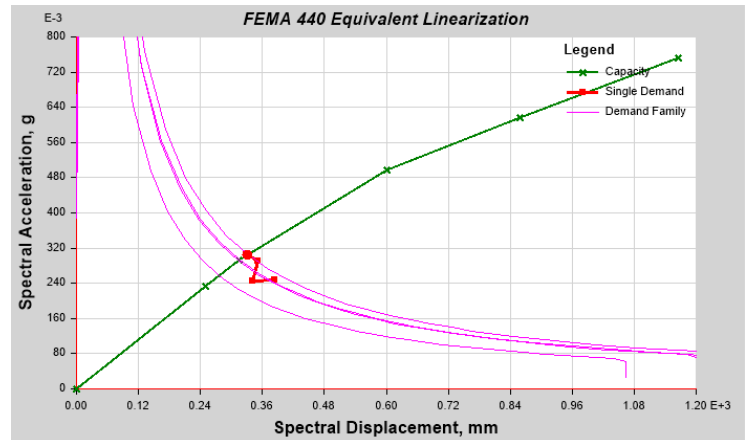

(b)

Gambar 4. Kurva pushover gedung 12 lantai (a) arah-X dan (b) arah-Y

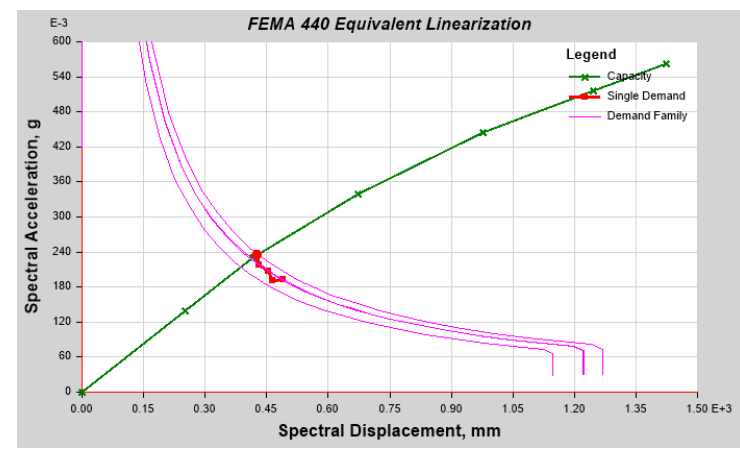

(a)

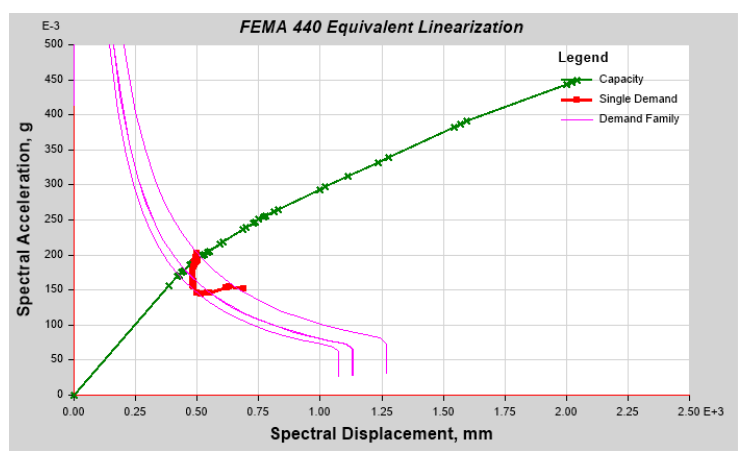

(b)

Gambar 5. Kurva pushover gedung 16 lantai (a) arah-X dan (b) arah-Y

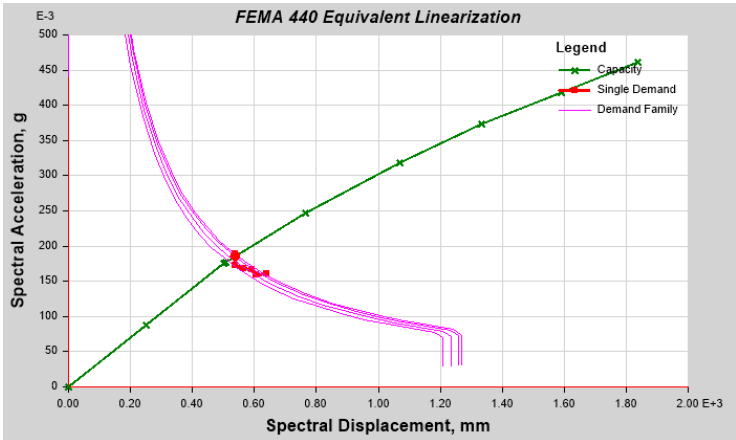

(a)

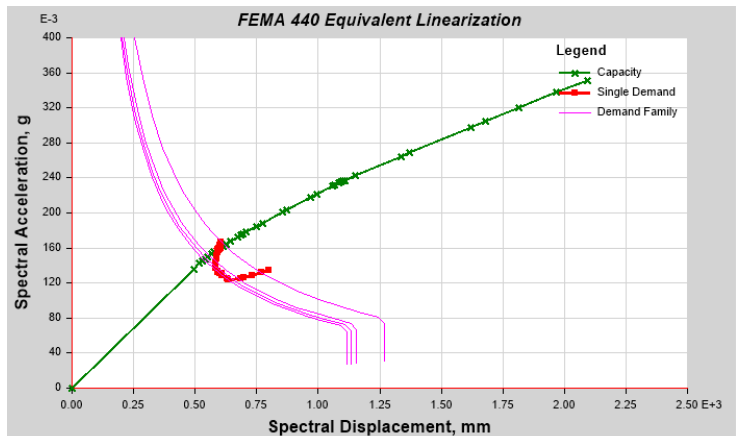

(b)

Gambar 6. Kurva pushover gedung 20 lantai (a) arah-X dan (b) arah-Y 


\section{KESIMPULAN DAN SARAN}

\subsection{Kesimpulan}

Dari hasil perhitungan dan analisis pada penelitian ini, dapat diambil kesimpulan sebagai berikut:

1. Dalam perencanaan apartemen 12, 16 dan 20 tingkat baik menggunakan bresing maupun tanpa menggunakan bresing sudah memenuhi persyaratan kekuatan dan simpangan izin. Taraf kinerja struktur yang didapat yaitu Immediate Occupacy (IO) dimana taraf ini diindikasikan kondisi struktur tidak ada kerusakan yang berarti dan struktur tetap dapat berfungsi tanpa terganggu masalah perbaikan.

2. Dari hasil analisis yang dilakukan, dapat dilihat bahwa perencanaan struktur baja menggunakan bresing mampu menahan gaya gempa yang bekerja. Struktur baja menggunakan bresing memliki sifat yang lebih kaku dibandingkan struktur baja tanpa bresing, hal ini dapat dibuktikan karena struktur yang menggunakan bresing memiliki perioda struktur yang lebih kecil dibandingkan struktur baja tanpa bresing.

3. Dari hasil-hasil analisis diatas dapat disimpulkan bahwa struktur yang lebih efektif yaitu struktur baja bertingkat 12 lantai dengan bresing konsentrik tipe Inverted- $\mathrm{V}$, dimana dapat dilihat dari perioda struktur yang lebih kecil dan berat struktur yang lebih kecil dibandingkan struktur lainnya.

\subsection{Saran}

Setelah melakukan penelitian ini, saran yang dapat penulis berikan bagi pengembangan penelitian ini ditahap selanjutnya adalah sebagai berikut:

1. Analisis sebaiknya dilakukan pada struktur yang lebih optimal dan sebaiknya pada bangunan existing atau bangunan yang sudah ada agar didapatkan hasil analisis pushover yang lebih jelas.

2. Perlu divariasikan lagi jumlah lantai dan untuk struktur yang tidak simetris agar dapat dibandingkan kinerja strukturnya.

3. Untuk pemilihan dimensi pada perencanaan struktur baja ini disarankan menggunakan profil baja ASTM agar didapatka penampang yang lebih optimal.

\section{DAFTAR RUJUKAN}

American Society of Civil Engineering. (2000). FEMA 356 Prestandard and Commentary for the Seismic Rehabilitation of Buildings. Virginia: American Society of Civil Engineering.

Aryandi, D. \& Herbudiman, B. (2017). Pengaruh Bentuk Bracing terhadap Kinerja Seismik Struktur Beton. Reka Racana, 3(1), 49.

Badan Standardisasi Nasional. (2012). SNI 1726:2012 tentang Tata Cara Perencanaan Ketahanan Gempa untuk Struktur Bangunan Gedung dan Non Gedung. Jakarta: Badan Standardisasi Nasional.

Badan Standardisasi Nasional. (2013). SNI 1727:2013 tentang Beban Minimum untuk Perancangan Bangunan Gedung dan Struktur Lain. Jakarta: Badan Standardisasi Nasional.

The University of Bristol. (2019, Agustus 8). IDEERS Resistant Building - Strengthening Bracing. Dipetik Agustus 8, 2019, dari IDEERS: http://www.ideers.bris.ac.uk/resistant/strength_brace_other.html 